\title{
NextGen Public Health Surveillance and the Internet of Things (IOT)
}

\author{
Kirti Sundar Sahu ${ }^{1}$, Shannon E. Majowicz ${ }^{1}$, Joel A. Dubin ${ }^{1,2}$ and \\ Plinio Pelegrini Morita ${ }^{1,3,4,5,6 *}$
}

${ }^{1}$ School of Public Health Sciences, University of Waterloo, Waterloo, ON, Canada, ${ }^{2}$ Department of Statistics and Actuarial Science, University of Waterloo, Waterloo, ON, Canada, ${ }^{3}$ Institute of Health Policy, Management, and Evaluation, University of Toronto, Toronto, ON, Canada, ${ }^{4}$ Department of Systems Design Engineering, University of Waterloo, Waterloo, ON, Canada, ${ }^{5}$ Ehealth Innovation, Techna Institute, University Health Network, Toronto, ON, Canada, ${ }^{6}$ Research Institute for Aging, University of Waterloo, Waterloo, ON, Canada

\section{OPEN ACCESS}

Edited by:

Celestine Iwendi,

University of Bolton, United Kingdom

Reviewed by:

Ebuka lbeke,

Robert Gordon University,

United Kingdom

Shweta Agrawal,

Sage University, India

Praveen Kumar,

VIT University, India

*Correspondence:

Plinio Pelegrini Morita

plinio.morita@uwaterloo.ca

Specialty section:

This article was submitted to

Digital Public Health,

a section of the journal

Frontiers in Public Health

Received: 10 August 2021 Accepted: 12 November 2021 Published: 03 December 2021

Citation:

Sahu KS, Majowicz SE, Dubin JA and Morita PP (2021) NextGen Public Health Surveillance and the Internet of

Things (IOT).

Front. Public Health 9:756675. doi: 10.3389/fpubh.2021.756675
Recent advances in technology have led to the rise of new-age data sources (e.g., Internet of Things (IoT), wearables, social media, and mobile health). IoT is becoming ubiquitous, and data generation is accelerating globally. Other health research domains have used loT as a data source, but its potential has not been thoroughly explored and utilized systematically in public health surveillance. This article summarizes the existing literature on the use of loT as a data source for surveillance. It presents the shortcomings of current data sources and how NextGen data sources, including the large-scale applications of loT, can meet the needs of surveillance. The opportunities and challenges of using these modern data sources in public health surveillance are also explored. These IOT data ecosystems are being generated with minimal effort by the device users and benefit from high granularity, objectivity, and validity. Advances in computing are now bringing loT-based surveillance into the realm of possibility. The potential advantages of loT data include high-frequency, high volume, zero effort data collection methods, with a potential to have syndromic surveillance. In contrast, the critical challenges to mainstream this data source within surveillance systems are the huge volume and variety of data, fusing data from multiple devices to produce a unified result, and the lack of multidisciplinary professionals to understand the domain and analyze the domain data accordingly.

Keywords: real-time data, rapid surveillance, data source, big data, innovation

\section{INTRODUCTION}

The function of public health systems is to understand and respond to health trends affecting populations (1). This is achieved through public health surveillance, that is, the ongoing collection and analysis of population health indicators. Traditional surveillance data collection can be cumbersome, expensive, and slow, often relying on paper-based and digitally extracted data sources. Social media and crowdsourcing are data sources that can be leveraged for surveillance data $(2,3)$. Sources like Twitter, Facebook, Google, and Reddit have been successfully used to explore behavior and health outcomes (4-6). These are now being accepted as potential data sources across several health domains $(7,8)$. 
Another promising data source is the increasing number of devices (e.g., smart home monitors, wearables) and the technology to interconnect them. Internet of Things (IoT) technologies have become mainstream within communities and individual households (9). Wearables and sensors can track personalized parameters of healthy living, including sleep, physical activity, and sedentary behavior $(10,11)$. These devices can provide insights into population health, disease management, and active assisted living services $(12,13)$. IoT data has several advantages over traditional surveillance data: high volume and frequency of data collection, data triangulation, real-time availability, and minimal acquisition effort.

Existing literature discusses the potential use of the IoT data sources for different purposes within multiple domains including healthcare. Among healthcare domain, area specific application can be seen for pediatric, geriatrics, chronic disease supervision, private health, and fitness management $(14,15)$, but no single study exists to put together the views to utilize the IoT data with specific emphasis on public health surveillance.

This article summarizes the existing literature on the use of IoT as a data source for surveillance. We discuss the shortcomings of current data sources and how IoT can meet the needs of surveillance. Challenges facing the large-scale application of IoT data to surveillance are also explored.

\section{PUBLIC HEALTH SURVEILLANCE AND CHALLENGES WITH EXISTING DATA SOURCES}

Public health recommendations focus on the social determinants of health and health equity (16). Surveillance is the process by which ongoing health data are collected, analyzed, and reported, and it is critical to informing public health services. In 1968, the World Health Organization listed 10 essential data sources for surveillance (17) (Figure 1: Traditional data sources) that at the time relied on paper-based data collection and manual data entry. Surveillance capability has evolved enormously alongside advances in technology. It now includes digital data extracted from several sources (Figure 1: Modern data sources), offering reduced processing time, fewer errors, and reduced lag between data collection and its use.

The above said, surveillance data are still often obtained from questionnaire-based surveys online surveys, in-person or telephone-based interviews (18), and such data collection requires enormous resources and funding $(19,20)$. Data quality can be compromised by declining response rates (18), recall bias (21), and low granularity of the data (22) as in the traditional data collection system, there is a limited number of subjects provide their inputs. Without complete and comprehensive information, the value of the data reduced. For example, fewer subjects with a smaller $n$, really only impacts the precision of the estimates that come from surveillance. To further explain, the system might not get very precise incidence estimates, which may or may not be a problem depending on the goal of the system. The bigger issue with declining response rates is that they usually do not happen at random and meaning you're a less representative set of results. This is an issue if the factors that lead to making it into surveillance also relate to the issue you are trying to measure with the surveillance system. Current data used for the surveillance have challenges like missing data, under-reporting, inconsistencies, invalid data, illegible handwriting, non-standardization of vocabulary, measurement error, and inappropriate fields (23). Traditional data sources used in surveillance are often delayed. For example, at least 1 year is required for getting a Canadian Community Health Survey (CCHS) update. "Public Health Ontario" in Canada affirms interdependent gaps within surveillance, insufficient data to build comprehensive health indicators (24), and an absence of existing mechanisms to capture some of healthcare's vital components.

Current surveillance relies on both prospective and retrospective data collection, analysis, and reporting (25). The current pandemic has highlighted the essential need for real-time public health surveillance to improve the evidencebased decision-making process (26). Our evolving knowledge about chronic diseases, their risk factors, and management also demands the modernization of surveillance (25). Real-time responses to emerging public health threats require real-time and systematic data collection.

\section{NEXT-GENERATION DATA SOURCES FOR PUBLIC HEALTH SURVEILLANCE}

Researchers have attempted to build and analyze health indicators using innovative data sources (27-29). They are exploring the use of smartphones (30), online searches (31), social media (7), wearables (32), ambient sensors (33), electronic health records (EHRs) $(27,34)$, medical-administrative records (27), and pharmacy sales (28) to broaden the scope of surveillance.

As a source of surveillance data, information technologies are potentially advantageous because their near-universal uptake by a significant portion of the population creates vast quantities and varieties of data (22). For example, wearable data from six billion nights has been used to understand sleep duration, quality, and change in pattern with time $(35,36)$. Effective use of big data for surveillance requires innovative analytical methods such as data integration (32) and data visualization (28, 37, 38). Big data analytics is becoming mainstream in public health, integrating knowledge and skills from health informatics and biostatistics (39).

\section{THE INTERNET OF THINGS AS A NOVEL DATA SOURCE}

The Internet of Things (IoT) is a technological innovation through which devices can communicate with each other in real-time through an internet connection (40). For example, several household devices are interconnected to achieve a common objective, such as monitoring temperature or motion (40). Integrated devices can include different sensors, mobile phones, mobile applications, 


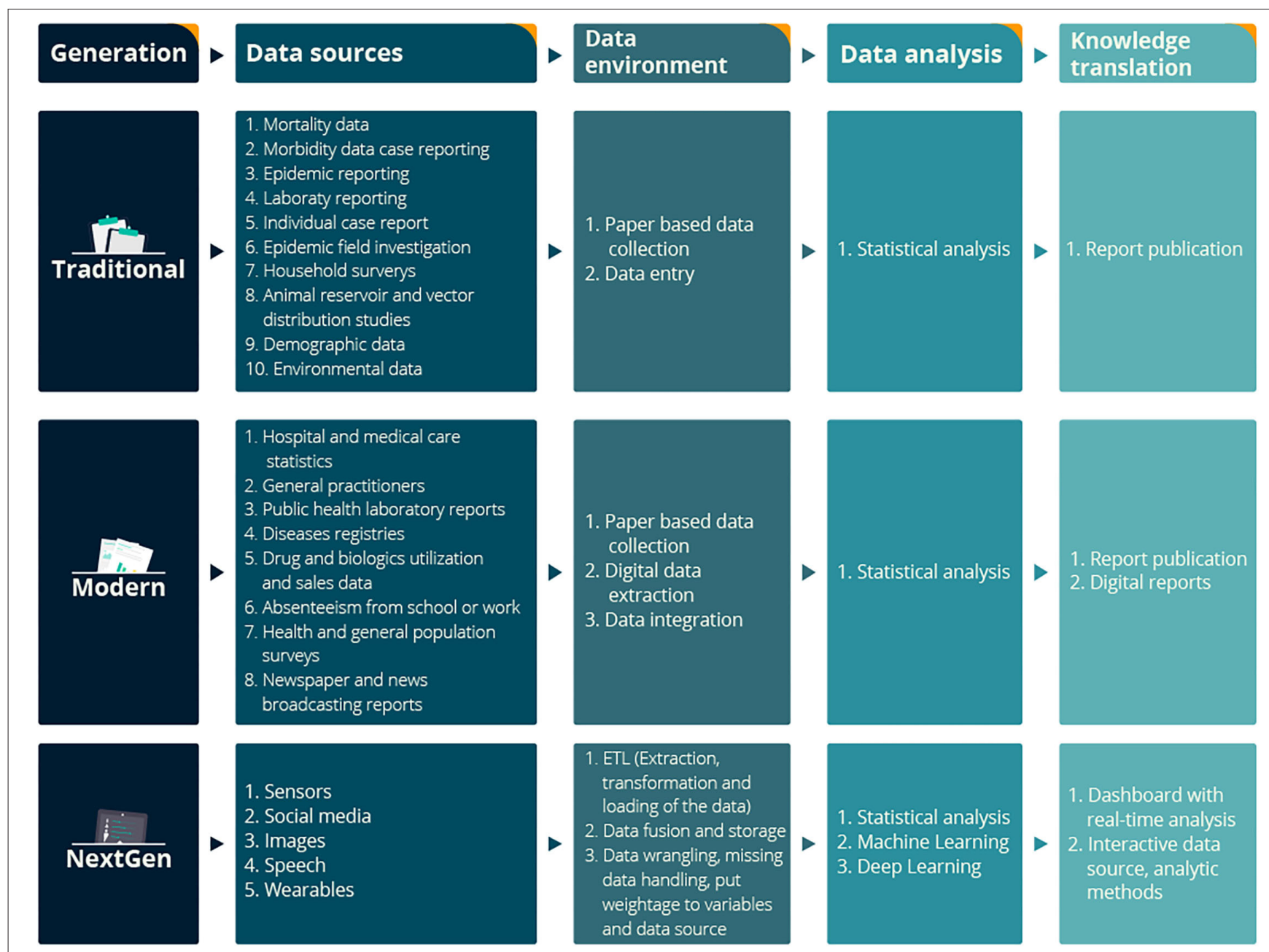

FIGURE 1 | Conceptual framework of NextGen Public Health Surveillance with Traditional, Modern, and NextGen data sources. Traditional and modern data sources extracted from Declich and Carter (17).

wearable devices, and Radio-Frequency Identification (RFID) tags (40).

IoT devices have accelerated data collection $(13,41)$. Connectivity among people, machines, and organizations increases as device availability and affordability improve (22). This increase in connectivity is because of the ease of use of the devices, user-friendly designs, and internet speed. These parameters reduced the time gap within communication, broaden the scope of communication by providing different choice, be it audio visual, text, or hybrid of multiple methods. People can interact with the machines and vice versa, which was not possible earlier due to lack of technological progress. In 2011, the number of interconnected devices overtook the actual number of people globally (42). The potential for data generation is exponential (41). As the IoT data has already been successfully used in multiple setups to monitor individual health outcomes and report on environmental conditions, some of the best use cases has been described below.

\section{Use of IoT Data to Support Individual Health Outcomes}

The management of chronic conditions has traditionally relied on patients interacting with their healthcare providers in person. However, patients spend most of their time outside the clinic. IoT monitoring provides an opportunity to collect real-time health information between patient-healthcare provider interactions.

Smart devices, such as wristbands, with IoT technology have been developed to measure individual physiological data, including physical activity $(10,43)$, sedentary time (44), oxygen saturation (45-47), heart rhythm $(45,46)$, muscle tremors (48), spinal posture (49), brainwaves (50), sleep (51), diet $(52,53)$, electrodermal activity monitoring for sympathetic response (44) and oral health care (54). With regards to specialized medical care, IoT technology has been used to cater to the need of cardiovascular (18), cardiopulmonary (18) and ophthalmology (55). With regards to different categories of populations, IoT has been used to help to monitor indicators related to women's health (56), including pregnancy (57), soldiers at the country borders 
(58), nursing care at the hospitals (59), the elderly population in the long-term-care homes (60), persons with neurological conditions at the rehabilitation center (49), and also for persons with respiratory complaints including asthma (61).

IoT devices have a multipurpose use within the healthcare field, such as their capabilities can range from providing prenatal care to rehabilitation to monitoring seniors or athletes. IoT devices have successfully provided real-time health information on maternal and fetal health between regular appointments (57). By monitoring vital signs using sensors, IoT platforms have been designed to provide people with diabetes with feedback and notifications to mitigate the risk of complications (62-64). Additionally, wearable devices have been used to detect falls and changes in behavioral activity for seniors living independently (65-68). Monitoring systems have also been developed to evaluate sports rehabilitation (69-72). IoT can support individual outcomes by allowing patients to manage their health outside of the clinical setting.

\section{Use of IoT Data to Monitor Environmental Conditions}

The IoT can also monitor environmental conditions in areas where we live, work, and play. Monitoring air purification in hospital settings plays a role in mitigating hospital-related infections (73). Monitoring air quality is already used to quantify climate change impact (74) and has the potential to help mitigate its impact in the future (75). IoT has been employed to monitor hospital circulating air volume, ozone concentration, temperature, humidity, and leaked ultraviolet intensity (73). Preventive behavior like hand washing can also be monitored (76). Indicators of healthy outdoor environments, such as water pollution and air quality, have been another target of IoT health research $(61,77,78)$.

\section{THE INTERNET OF THINGS IN PUBLIC HEALTH SURVEILLANCE}

IoT data has been successfully used in other health domains but has not yet been fully used in public health. In response to the pandemic, the 2020 Riyadh Declaration made several recommendations to address the shortcomings in global public health response systems (79). The Declaration prioritized the need for scalable and sustainable digital health technologies and the adoption of health intelligence (79). There is a growing interest in using IoT data for building public health indicators at various levels (80-82).

\section{Advantages of loT in Public Health Surveillance}

IoT data have the potential to overcome shortcomings of current surveillance. IoT data sources provide high-frequency data with greater usability, and much of the device infrastructure for surveillance is already in place (i.e., smartphones, wearable technologies, internet access). Currently, worldwide more than three billion smartphone users (83), 722 million users of several kinds of wearable devices (84), and more than 1.2 billion smarthome connected devices exist (85). IoT data benefits from essential features like high granularity (22), objectivity (32), and validity (86). These "user-generated data ecosystems" are being generated with minimal effort by the device users and researchers. To date, the monetary cost to participants and researchers is low, suggesting that public health monitoring costs would likewise be minimal $(87,88)$. Finally, IoT enables near real-time data collection (89). This can significantly reduce the time gap between health events, data collection, reporting, and intervention.

Here we have assessed IoT's current attributes using the framework for evaluating public health surveillance by Groseclose et al. (90), which outlines nine features of surveillance systems to consider (Table 1). As summarized in the table, the major advantages of IoT data sources appear to be highfrequency data collection, the potential to have syndromic surveillance, zero effort data collection method, high volume, and variety of data. The major disadvantages appear to be lack of representativeness within a single data source, private players' involvement as the data owner, the need for a high technological system to store, clean, and analyze the data, and interoperability. In addition to the above points, data privacy concerns of users are a potential disadvantage of acceptance of this technology from the user point of view (81).

\section{Challenges to Using loT in Public Health Surveillance}

The challenge now is how to access and analyze the data being gathered. Some IoT companies create sharable, researchoriented data sources, such as "donate your data" from ecobee, a smart thermostat company in Canada (91). ecobee's smart home products include motion and temperature sensors, and research teams have access to longitudinal data from thousands of households with a data granularity of 5 min intervals.

Other IoT companies publish studies from their own smart devices using artificial intelligence algorithms for populationlevel measurements. For example, Fitbit wearables recorded sleep data from over six billion nights of its customers' sleep (35), the most prominent sleep dataset ever collected. Similarly, Oura Health used IoT data gathered from their Oura ring, a wearable sensor that tracks key signals from the human body (sleep, heart rate, skin temperature, physical activity), delivering critical insights to help an individual harness their body's potential daily and also to monitor vital health indicators (92).

Another hurdle is the ability to fuse data from multiple devices to produce a unified result. Several research projects have focused on making IoT data fusion viable in the real world by designing computing infrastructure and data fusion techniques $(89,93)$. Real-time IoT analysis from multiple health monitoring devices may overwhelm current computational capabilities, such as using multiple devices to monitor each football player's physiological indicators during a game (94). A distributed computational framework to handle complex computational needs was developed by Higinio et al. for health surveillance (94). 
TABLE 1 | Analysis of loT as a data source for public health surveillance, using Groseclose et al. (90) framework for evaluating public health surveillance.

\section{Attributes (definition) Features of loT data}

\section{Simplicity}

"The system's structure and ease of operation. The system should be as simple as possible." (90)

\section{Flexibility}

"Ability to adapt to changing information needs or technological operating conditions with little additional time, personnel, or allocated funds." (90)

\section{Data quality}

"Completeness and validity of the data recorded in the system." (90)

\section{Acceptability}

"Willingness of persons and organizations to participate in the system." (90)

\section{Sensitivity}

"At the level of case reporting: the proportion of cases of a disease or event detected by the system. Ability to detect outbreaks over time and evaluation of surveillance system." (90)

\section{Positive predictive value} "The proportion of reported cases that actually have the event under surveillance." (90)

\section{Representativeness} "Ability to accurately describe the occurrence of a health-related event overtime and distribution of the population by place and person." (90)

\section{Timeliness}

"Reflects the speed between steps in a system." (90)

\section{Stability}

"Ability to rely on the system for availability and to collect manage and provide data without failure. Ability to be operational when needed." (90)
- Data collection/extraction from users without complex interactions using Application Programming Interface (APIs) that the manufacturer often provides.

- Easy access to the data, which is often collected by passive sensors, minimizing the burden for the user.

- IOT systems rapidly generate large volumes of data in real-time, creating challenges associated with managing, hosting, and analyzing big data.

- Diverse types of data being generated: numeric, images, text, or audio.

- Collects vast amounts of data from the same individual, often supporting longitudinal analysis.

- Application Programming Interfaces (APIs) make it easy to adapt to the technology to the end-users being used, type of data, type of database, type of storage, and security requirements.

- New loT data sources that use APIs can easily be integrated into systems, also affording changes in a data structure as technologies evolve.

- Changes in case definition can be updated in algorithms rather than requiring changes to data collected since systems can access the raw data.

- The system can be automated to generate alert systems without manual effort which can help public health officials identify potential signals for future outbreaks early.

- IoT data often suffers from missing, inaccurate, and incomplete data.

- Wearable sensors that require participants to recharge and remember to interact with the device often have larger volumes of missing data.

- Ambient sensors often generate continuous and complete datasets as they are always connected, powered on, and streaming.

- Technology development is leading to improved data quality across all loT sensors.

- IoT technologies are pervasive, and in the community, a part of the population is already using those technologies to generate data.

- loT adoption is accelerating in the last decade and is predicted to be much higher in the near future.

- Recent advancement in technology used "skin interfaced sensors" not only monitor physical activities and vital signs but also keep track of molecular biomarkers of the human body (104).

- Users need to agree to share their data, as it has already been collected.

- IoT sensors, in most cases, do not focus on the detection of specific diseases such as COVID-19 or influenza but rather on symptoms like fever, abnormal heart rate, or change in gait pattern.

- IOT technology is ideal for supporting syndromic surveillance by collecting data about healthy behaviors and health variables in real-time.

- IoT technology will collect data that is often indirectly associated with health and health risk behaviors (e.g., indoor motion data to quantify sleep patterns, phone mobility data used to quantify response to COVID-10 policies).

- IoT will provide extensive participant data with a higher likelihood of the presence of events.

- The longitudinal nature of the data can detect future anomalies using Artificial Intelligence models within the healthcare sector and send alerts to policymakers. The longitudinal and continuity nature of the data will provide richer insights into population behaviors, which increases the likelihood of getting the events of interest.

- The proportion of the presence of loT within the community is increasing and predicting the true positive cases will be easier using IOT data by identifying early alerts.

- The detection of specific diseases is possible, as technologies such as lab on a chip (106, 107) allow for real-time detection of pathogens and contaminants.

- Positive predictive value seems to be in a disadvantageous position with the current loT data environment, but this might change in the future.

- Large number of participants can provide access to data who were not represented in the traditional data collection method.

- IoT technologies are ubiquitous, highly pervasive, and are generating data 24/7.

- Data mining from sensors already owned by the population generates a biased sample, with data from the wealthier and more physically active part of the population.

- Studies can supplement biased samples by deploying targeted studies to collect data from under-represented subgroups of the population.

- Data is often collected at high frequencies, often affording access to data in the near real-time.

- An increase in the data's granularity and the longitudinal nature of the data can provide richer insights, for instance, faster alerts of anomalies for specific health issues, and support the creation of innovative indicators.

- In the near future, the loT data source may become helpful to identify future pandemic and climate-related emergencies. Immediate assessment of the impact of policy changes (for example, "work from home" during the pandemic) can be possible using loT data.

- Improvement from traditional data sources where data collection often happens once yearly or less frequently.

- Private cloud systems can provide the necessary data security and maintain the users' privacy.

- Redundant, always available, more stable public health surveillance platforms/systems can be built using private cloud solutions, having the capacity to collect uninterrupted data without failure. IOT manufacturers and loT data custodians can deliver such redundant and stable systems for their consumers' everyday use.

- The disadvantage of these loT data manufacturers is ever-changing company environment (for example, corporate and big private entities) might not provide a stable source of data. The alternative source of data should be listed as a backup plan to support and strengthen when required.

\#Groseclose et al. (90). 
The use of each smart devices' computing capabilities effectively shared advanced health monitoring applications (94).

Regarding technical challenges related to IoT, some of the critical issues are energy optimization, hardware compatibility, security, and data connectivity (95). A recent study by Iwendi et al. in 2020 shows that there are certain highly specialized algorithm such as a "hybrid meta-heuristic algorithm" has the potential to optimize the energy consumption of the sensors related to wireless sensor networks (95).

Aberration detection identifies unusual incidents or information trends with possible significance to clinical or public health (96). Methods for detecting such aberrations have also evolved significantly. Current modeling methods can now analyze individual surveillance data collected from different sources and integrate multiple covariates (97). The algorithms used for signal recognition have improved over the last decade and are now better equipped to utilize advanced informatics to capture surveillance data aberrations $(96,97)$ accurately.

In 2018, Faverjon C. and Berezowski J. elaborated on IoT data's utility for aberration detection $(97,98)$. Two studies have shown that user data from wearables (Fitbit and the Oura ring) could detect early signs of COVID-19 infection (99-103). Evidence shows the risk of hospitalization related to COVID-19 can be calculated from self-reported symptoms and predictive physiological signs by combining different health and behavioral data from consumer wearable devices; this may help identify pathological changes weeks before observation using traditional epidemiological monitoring $(99,100)$. As described in the study using Fitbit wearable, it has the potential to detect almost half of COVID-19 positive cases $24 \mathrm{~h}$ before participants reported the onset of symptoms with 70 percent specificity (103). Besides joint effort by multiple countries to develop vaccines and potential drugs to prevent and treat COVID-19, skin-integrated and skin interfaced sensors, positioned at optimal locations of the body, might address the ongoing and critical need for objective, continuous, and sensitive tools to detect COVID-19 symptoms early in the general population $(101,104)$. A research study highlighted a practical approach for managing epidemics using digital technologies with a roadmap to a rapid and universal diagnostic method for the population level detection of several respiratory infections in advance of symptoms (102). These anomalies could predict future outbreaks (97) and prevent the spread of infectious diseases (105).

\section{NEXTGEN PUBLIC HEALTH SURVEILLANCE}

The COVID-19 pandemic has revealed a need to strengthen our public health surveillance and response systems. With the availability of public data and advances in collection and analysis, there is an opportunity to strengthen existing surveillance

\section{REFERENCES}

1. Choi BCK. The past, present, and future of public health surveillance. Scientifica. (2012) 2012:1-26. doi: 10.6064/2012/875253 systems by harnessing complementary data sources like IoTbased data (31).

Figure 1 describes the NextGen surveillance systems' conceptual framework. The first layer describes the sources of public health data. The second layer represents the data architecture. Once the data integration process is completed, data manipulation and analysis can be possible using statistics, machine learning, and deep learning algorithms. This process will help discover new public health indicators and advance our understanding of existing disease risk factors.

\section{CONCLUSION}

Current public health surveillance systems have unique challenges in getting the relevant data at the right time and utilizing those data sources for policy-level decision-making. There is a considerable volume of non-traditional data being self-generated by the public through their ubiquitous use of smart devices. Public health has the potential to utilize the real-time, longitudinal data collected through the Internet of Things (IoT) necessary for health surveillance. Advances in computing are now bringing IoT-based surveillance into the realm of possibility. The advantages of IoT data include high-frequency, high volume, zero effort data collection method, with a potential to have syndromic surveillance.

\section{DATA AVAILABILITY STATEMENT}

The original contributions presented in the study are included in the article/supplementary material, further inquiries can be directed to the corresponding author.

\section{AUTHOR CONTRIBUTIONS}

KS and PM developed the theoretical framework for the paper. PM supervised KS for the project. KS wrote the first draft of the manuscript with input from all authors. SM and JD helped provide overall direction and planning. All authors contributed to manuscript reading and revision and have approved the submitted version.

\section{FUNDING}

This work was supported by Natural Sciences and Engineering Research Council of Canada (RPGIN-2017-05310) and the Ontario Centre of Innovation (33080).

\section{ACKNOWLEDGMENTS}

Thanks to all the team members of Ubilab, at the University of Waterloo, for their support.

2. Wazny K. Applications of crowdsourcing in health: an overview. J Glob Health. (2018) 8:010502. doi: 10.7189/jogh.08.010502

3. Kraemer JD, Strasser AA, Lindblom EN, Niaura RS, Mays D. Crowdsourced data collection for public health: a comparison with 
nationally representative, population tobacco use data. Prev Med. (2017) 102:93-9. doi: 10.1016/j.ypmed.2017.07.006

4. Dalton CB. Enablers of innovation in digital public health surveillance: lessons from flutracking. Int Health. (2017) 9:145-7. doi: 10.1093/inthealth/ihx009

5. Gittelman S, Lange V, Gotway Crawford CA, Okoro CA, Lieb E, Dhingra SS, et al. A new source of data for public health surveillance: facebook likes. $J$ Med Internet Res. (2015) 17:e98. doi: 10.2196/jmir.3970

6. Bagroy S, Kumaraguru P, De Choudhury M. A Social Media Based Index of Mental Well-Being in College Campuses. New York, NY: ACM Press (2017).

7. Edo-Osagie O, De La Iglesia B, Lake I, Edeghere O. A scoping review of the use of twitter for public health research. Comput Biol Med. (2020) 122:103770. doi: 10.1016/j.compbiomed.2020.103770

8. Sinnenberg L, Buttenheim AM, Padrez K, Mancheno C, Ungar L, Merchant RM. Twitter as a tool for health research: a systematic review. Am J Public Health. (2017) 107:e1-8. doi: 10.2105/AJPH.2016.303512a

9. Plageras AP, Psannis KE, Ishibashi Y, Kim BG. IoT-based surveillance system for ubiquitous healthcare. In: IECON Proceedings (Industrial Electronics Conference) (Florence: IEEE Computer Society).

10. Qi J, Yang P, Waraich A, Deng Z, Zhao Y, Yang Y. Examining sensorbased physical activity recognition and monitoring for healthcare using internet of things: a systematic review. J Biomed Inform. (2018) 87:13853. doi: 10.1016/j.jbi.2018.09.002

11. Sahu KS, Oetomo A, Morita PP. Enabling remote patient monitoring through the use of smart thermostat data in canada: exploratory study. JMIR Mhealth Uhealth. (2020) 8:e21016. doi: 10.2196/21016

12. Talal M, Zaidan AA, Zaidan BB, Albahri AS, Alamoodi AH, Albahri OS, et al. Smart home-based iot for real-time and secure remote health monitoring of triage and priority system using body sensors: multi-driven systematic review. J Med Syst. (2019) 43:42. doi: 10.1007/s10916-019-1158-z

13. Asghari P, Rahmani AM, Javadi HHS. Internet of things applications: a systematic review. Comput Networks. (2019) 148:241-61. doi: 10.1016/j.comnet.2018.12.008

14. Bhuiyan MN, Rahman MM, Billah MM, Saha D. Internet of things (IoT): a review of its enabling technologies in healthcare applications, standards protocols, security, and market opportunities. IEEE Internet Things J. (2021) 8:10474-98. doi: 10.1109/JIOT.2021.3062630

15. Riazul Islam SM, Kwak D, Humaun Kabir M, Hossain M, Kwak KS. The internet of things for health care: a comprehensive survey. IEEE Access. (2015) 3:678-708. doi: 10.1109/ACCESS.2015.2437951

16. DeSalvo KB, O'Carroll PW, Koo D, Auerbach JM, Monroe JA. Public health 3.0: time for an upgrade. Am J Public Health. (2016) 106:6212. doi: 10.2105/AJPH.2016.303063

17. Declich S, Carter AO. Public health surveillance: historical origins, methods and evaluation. Bull World Health Organ. Geneva (1994) 72:285-304.

18. IOM (Institute of Medicine). A Nationwide Framework for Surveillance of Cardiovascular and Chronic Lung Diseases. Washington, DC: National Academies Press (2011).

19. Frieden TR, Harold Jaffe DW, Thacker SB, Moolenaar RL, Lee LM, Meyer PA, et al. CDC's Vision for Public Health Surveillance in the 21st Century. Atlanta: Centers for Disease Control and Prevention(2012).

20. Rosenman R, Tennekoon V, Hill LG. Measuring bias in self-reported data. Int J Behav Healthc Res. (2011) 2:320-32. doi: 10.1504/IJBHR.2011.043414

21. Coughlin SS. Recall bias in epidemiologic studies. J Clin Epidemiol. (1990) 43:87-91. doi: 10.1016/0895-4356(90)90060-3

22. Bansal S, Chowell G, Simonsen L, Vespignani A, Viboud C. Big data for infectious disease surveillance and modeling. J Infect Dis. (2016) 214:S3759. doi: 10.1093/infdis/jiw400

23. Chen H, Hailey D, Wang N, Yu P. A review of data quality assessment methods for public health information systems. Int J Environ Res Public Health. (2014) 11:5170-207. doi: 10.3390/ijerph110505170

24. Public Health Ontario. Gaps in Public Health Indicators and Data in Ontario. Revised ed. Toronto, ON (2016). Available online at: https://www. publichealthontario.ca/-/media/documents/public-health-indicator-gaps. pdf?la=en (accessed February 22, 2019).

25. Chretien JP, Tomich NE, Gaydos JC, Kelley PW. Real-time public health surveillance for emergency preparedness. Am J Public Health. (2009) 99:1360-3. doi: 10.2105/AJPH.2008.133926
26. Buehler JW, Centers for Disease Control and Prevention. CDC's vision for public health surveillance in the 21st century. Introduction. MMWR Suppl. (2012) 61:1-2.

27. Seeskin ZH, LeClere F, Ahn J, Williams J. Uses of Alternative Data Sources for Public Health Statistics and Policymaking: Challenges and Opportunities. (2018). Available online at: https://www.norc.org/PDFs/Publications/ SeeskinZ_UsesofAlternativeDataSources_2018.pdf (accessed August 24, 2020).

28. Groseclose SL, Buckeridge DL. Public health surveillance systems: recent advances in their use and evaluation. Annu Rev Public Health. (2017) 38:57-79. doi: 10.1146/annurev-publhealth-031816-044348

29. Althouse BM, Scarpino S V, Meyers LA, Ayers JW, Bargsten M, Baumbach J, et al. Enhancing disease surveillance with novel data streams: challenges and opportunities. EPJ Data Sci. (2015) 4:17. doi: 10.1140/epjds/s13688-015-0054-0

30. Navin K, Krishnan MBM, Lavanya S, Shanthini A. A mobile health based smart hybrid epidemic surveillance system to support epidemic control programme in public health informatics. In: IEEE International Conference on IoT and its Applications, ICIOT. (Nagapattinam: Institute of Electrical and Electronics Engineers Inc.) (2017).

31. Mancuso M, Yao X, Otchere D, Rasali D, Clark E, Svenson LW, et al. Proof of concept paper: non-traditional data sources for public health surveillance. In: DH - Proceedings of the 2016 Digital Health Conference. New York, NY: Association for Computing Machinery, Inc. (2016).

32. LaMunion SR, Fitzhugh EC, Crouter SE. Challenges and opportunities related to the objective assessment of physical activity within U.S. health surveys. Ann Epidemiol. (2020) 43:1-10. doi: 10.1016/j.annepidem.2020.01.011

33. Lamiae E, Fatiha E, Mohammed B, Hicham GT. Contribution to a Smart Home Design for Medical Surveillance. Cham: Springer.

34. Huang J, Loschen W. Potential applications of emerging technologies in disease surveillance. Online J Public Health Inform. (2019) 11:e340. doi: 10.5210/ojphi.v11i1.9821

35. Pogue D. What Fitbit Discovered From 6 Billion Nights of Sleep Data. Yahoo. (2018). Available online at: https://uk.finance.yahoo.com/news/ exclusive-fitbits-6-billion-nights-sleep-data-reveals- us-110058417.html? guccounter=1\&guce_referrer=aHR0cHM6Ly93d3cud2Vmb3J1bS (accessed March 2, 2020).

36. Haghayegh S, Khoshnevis S, Smolensky MH, Diller KR, Castriotta RJ. Accuracy of wristband fitbit models in assessing sleep: systematic review and meta-analysis. J Med Internet Res. (2019) 21:e16273. doi: 10.2196/16 273

37. DeSalvo KB, Wang YC, Harris A, Auerbach J, Koo D, O’Carroll P. Public health 3.0: a call to action for public health to meet the challenges of the 21st century. Prev Chronic Dis. (2017) 14:170017. doi: 10.5888/pcd14.170017

38. Zeng D, Cao Z, Neill DB. Artificial intelligence-enabled public health surveillance-from local detection to global epidemic monitoring and control. Artif Intell Med. (2021):43753. doi: 10.1016/B978-0-12-821259-2.00022-3

39. Chiolero A, Buckeridge D. Glossary for public health surveillance in the age of data science. J Epidemiol Community Health. (2020) 74:6126. doi: 10.1136/jech-2018-211654

40. Atzori L, Iera A, Morabito G. The internet of things: a survey. Comput Networks. (2010) 54:2787-805. doi: 10.1016/j.comnet.2010.05.010

41. Steele R, Clarke A. The internet of things and next-generation public health information systems. Commun Netw. (2013) 5:4-9. doi: 10.4236/cn.2013.53B1002

42. Gubbi J, Buyya R, Marusic S, Palaniswami M. Internet of things (IoT): a vision, architectural elements, and future directions. Futur Gener Comput Syst. (2013) 29:1645-60. doi: 10.1016/j.future.2013.01.010

43. Subasi A, Radhwan M, Kurdi R, Khateeb K. IoT based mobile healthcare system for human activity recognition. In: 15th Learning and Technology Conference, $L$ and T. Jeddah: Institute of Electrical and Electronics Engineers Inc. (2018).

44. Hilty DM, Armstrong CM, Luxton DD, Gentry MT, Krupinski EA. A scoping review of sensors, wearables, and remote monitoring for behavioral health: uses, outcomes, clinical competencies, and research directions. J Technol Behav Sci. (2021) 6:1-36. doi: 10.1007/s41347-021-00199-2 
45. Marques G, Roque Ferreira C, Pitarma R. A system based on the internet of things for real-time particle monitoring in buildings. Int J Environ Res Public Health. (2018) 15:821. doi: 10.3390/ijerph15040821

46. Li SH, Lin BS, Wang CA, Yang CT, Lin BS. Design of wearable and wireless multi-parameter monitoring system for evaluating cardiopulmonary function. Med Eng Phys. (2017) 47:144-150. doi: 10.1016/j.medengphy.2017.06.009

47. Adiputra RR, Hadiyoso S, Hariyani YS. Internet of things: low cost and wearable SpO2 device for health monitoring. Int J Electr Comput Eng. (2018) 8:939-45. doi: 10.11591/ijece.v8i2.pp939-945

48. Chiuchisan I, Geman O. An approach of a decision support and home monitoring system for patients with neurological disorders using internet of things concepts. WSEAS Trans Syst. (2014) 13:460-9.

49. Nam KH, Kim DH, Choi BK, Han IH. Internet of things, digital biomarker, and artificial intelligence in spine: current and future perspectives. Neurospine. (2019) 16:705-11. doi: 10.14245/ns.1938388.194

50. de Oliveira WG Jr, de Oliveira JM, Munoz R, de Albuquerque VHC. A proposal for internet of smart home things based on BCI system to aid patients with amyotrophic lateral sclerosis. Neural Comput Appl. (2020) 32:11007-17. doi: 10.1007/s00521-018-3820-7

51. Surantha N, Kusuma GP, Isa SM. Internet of things for sleep quality monitoring system: a survey. In: Proceedings - 11th. International Conference on Knowledge, Information and Creativity Support Systems, KICSS. Yogyakarta: Institute of Electrical and Electronics Engineers Inc. (2016).

52. Iwendi C, Khan S, Anajemba JH, Bashir AK, Noor F. Realizing an efficient IoMT-assisted patient diet recommendation system through machine learning model. IEEE Access. (2020) 8:2846274. doi: 10.1109/ACCESS.2020.2968537

53. Mantey EA, Zhou C, Anajemba JH, Okpalaoguchi IM, Chiadika OD. Blockchain-secured recommender system for special need patients using deep learning. Front Public Heal. (2021) 9:737269. doi: 10.3389/fpubh.2021.737269

54. Salagare S, Prasad R. An overview of internet of dental things: new frontier in advanced dentistry. Wirel Pers Commun. (2020) 110:134571. doi: 10.1007/s11277-019-06790-4

55. Ting DSW, Lin H, Ruamviboonsuk P, Wong TY, Sim DA. Artificial intelligence, the internet of things, and virtual clinics: ophthalmology at the digital translation forefront. Lancet Digit Heal. (2020) 2:e89. doi: 10.1016/S2589-7500(19)30217-1

56. Yoldemir T. Internet of things and women's health. Climacteric. (2020) 23:423-5. doi: 10.1080/13697137.2020.1811563

57. Saarikko J, Niela-Vilen H, Ekholm E, Hamari L, Azimi I, Liljeberg P, et al. Continuous 7-month internet of things-based monitoring of health parameters of pregnant and postpartum women: prospective observational feasibility study. JMIR Form Res. (2020) 4:e12417. doi: 10.2196/12417

58. Patil N, Iyer B. Health monitoring and tracking system for soldiers using Internet of Things(IoT). In: Proceeding - IEEE International Conference on Computing, Communication and Automation, ICCCA. Greater Noida: Institute of Electrical and Electronics Engineers Inc. (2017).

59. Mieronkoski R, Azimi I, Rahmani AM, Aantaa R, Terävä V, Liljeberg P, et al. The Internet of Things for basic nursing care-A scoping review. Int J Nurs Stud. (2017) 69:78-90. doi: 10.1016/j.ijnurstu.2017.01.009

60. Finch M, Griffin K, Pacala JT. Reduced healthcare use and apparent savings with passive home monitoring technology: a pilot study. J Am Geriatr Soc. (2017) 65:1301-05. doi: 10.1111/jgs.14892

61. Isaac N, Sampath N, Gay V. SAM smart asthma monitoring: focus on air quality data and Internet of Things (IoT). In: International Symposium on Medical Information and Communication Technology, ISMICT. Sydney: IEEE Computer Society.

62. Alelyani S, Ibrahim A. Internet-of-things in telemedicine for diabetes management. In: 15th Learning and Technology Conference, $L$ and $T$. Institute of Electrical and Electronics Engineers Inc.) (2018).

63. Bruen D, Delaney C, Florea L, Diamond D. Glucose sensing for diabetes monitoring: recent developments. Sensors. (2017) 17:1866. doi: 10.3390/s17081866

64. Al-Taee MA, Al-Nuaimy W, Al-Ataby A, Muhsin ZJ, Abood SN. Mobile health platform for diabetes management based on the internet-of-things. In: IEEE Jordan Conference on Applied Electrical Engineering and Computing
Technologies, AEECT. The Dead Sea: Institute of Electrical and Electronics Engineers Inc. (2015).

65. Ben Hassen H, Dghais W, Hamdi B. An E-health system for monitoring elderly health based on internet of things and fog computing. Heal Inf Sci Syst. (2019) 7:24. doi: 10.1007/s13755-019-0087-z

66. Hosseinzadeh M, Koohpayehzadeh J, Ghafour MY, Ahmed AM, Asghari P, Souri A, et al. An elderly health monitoring system based on biological and behavioral indicators in internet of things. J Ambient Intell Humaniz Comput. (2020) 1:3. doi: 10.1007/s12652-020-02579-7

67. Yacchirema D, De Puga JS, Palau C, Esteve M. Fall detection system for elderly people using IoT and big data. Procedia Comput Sci. (2018) 130:60310. doi: 10.1016/j.procs.2018.04.110

68. Dohr A, Modre-Opsrian R, Drobics M, Hayn D, Schreier G. The internet of things for ambient assisted living. In: Seventh International Conference on Information Technology: New Generations (Porto: IEEE) (2010).

69. Zhan K. Sports and health big data system based on $5 \mathrm{G}$ network and Internet of Things system. Microprocess Microsyst. (2021) 80:103363. doi: 10.1016/j.micpro.2020.103363

70. Zhao Y, You Y. Design and data analysis of wearable sports posture measurement system based on Internet of Things. Alexandria Eng J. (2021) 60:691-701. doi: 10.1016/j.aej.2020.10.001

71. Liu L. Construction of youth public sports service system based on embedded system and wireless IoT. Microprocess Microsyst. (2021) 83:103984. doi: 10.1016/j.micpro.2021.103984

72. Jiang Y. Combination of wearable sensors and internet of things and its application in sports rehabilitation. Comput Commun. (2020) 150:16776. doi: 10.1016/j.comcom.2019.11.021

73. Yang L, Yao T, Liu G, Sun L, Yang N, Zhang H, et al. Monitoring and control of medical air disinfection parameters of nosocomial infection system based on Internet of Things. J Med Syst. (2019) 43:126. doi: 10.1007/s10916-019-1205-9

74. USGCRP. Impacts, risks, adaptation in the United States: the fourth national climate assessment. Volume II. In: Reidmiller DR, Avery CW, Easterling DR, Kunkel KE, Lewis KLM, Maycock TK, Stewart B. U.S. Global Change Research Program. Washington, DC: United Nations Office for Disaster Risk Reduction (2018).

75. Múnera D, Diana V, Aguirre J, Gómez NG. IoT-based air quality monitoring systems for smart cities: a systematic mapping study. Int J Electr Comput Eng. (2021) 11:3470-82. doi: 10.11591/ijece.v11i4.pp34703482

76. Bal M, Abrishambaf R. A system for monitoring hand hygiene compliance based-on Internet-of-Things. In: Proceedings of the IEEE International Conference on Industrial Technology. Toronto: Institute of Electrical and Electronics Engineers Inc.

77. Shafi U, Mumtaz R, Anwar H, Qamar AM, Khurshid H. Surface water pollution detection using Internet of Things. In: 15th International Conference on Smart Cities: Improving Quality of Life Using ICT and IoT, HONET-ICT. Institute of Electrical and Electronics Engineers Inc. (2018).

78. Agarwal A, Shukla V, Singh R, Gehlot A, Garg V. Design and development of air and water pollution quality monitoring using iot and quadcopter. Adv Intell Syst Comput. (2018) 624:485-92. doi: 10.1007/978-981-10-59032_49

79. Al Knawy B, Adil M, Crooks G, Rhee K, Bates D, Jokhdar H, et al. The riyadh declaration: the role of digital health in fighting pandemics. Lancet. (2020) 396:1537-9. doi: 10.1016/S0140-6736(20)319 78-4

80. Aiello AE, Renson A, Zivich PN. Social media-and internet-based disease surveillance for public health. Annu Rev Public Heal. (2020) 41:10118. doi: 10.1146/annurev-publhealth-040119-094402

81. Mooney SJ, Pejaver V. Big data in public health: terminology, machine learning, and privacy. Annu Rev Public Health. (2018) 39:95-112. doi: 10.1146/annurev-publhealth-040617-014208

82. Hung K, Zhang YT. Implementation of a WAP-based telemedicine system for patient monitoring. IEEE Trans Inf Technol Biomed. (2003) 7:1017. doi: 10.1109/TITB.2003.811870

83. Statista. Smartphone Users. (2020). Available online at: https://www.statista. com/statistics/330695/number-of-smartphone-users-worldwide/ (accessed April 16, 2021). 
84. Statista. Global Connected Wearable Devices 2016-2022. (2021). Available online at: https://www.statista.com/statistics/487291/global-connectedwearable-devices/ (accessed April 16, 2021).

85. Statista. Global Smart Home Market Size 2016-2022. (2021). Available online at: https://www.statista.com/statistics/682204/global-smart-home-marketsize/ (accessed April 16, 2021).

86. Park HA, Jung H, On J, Park SK, Kang H. Digital epidemiology: use of digital data collected for non-epidemiological purposes in epidemiological studies. Healthc Inform Res. (2018) 24:253. doi: 10.4258/hir.2018.24.4.253

87. Grace SL, Taherzadeh G, Jae Chang IS, Boger J, Arcelus A, Mak S, et al. Perceptions of seniors with heart failure regarding autonomous zero-effort monitoring of physiological parameters in the smart-home environment. Hear Lung J Acute Crit Care. (2017) 46:313-9. doi: 10.1016/j.hrtlng.2017.04.007

88. Mihailidis A, Boger J, Hoey J, Jiancaro T. Zero effort technologies: considerations, challenges, and use in health, wellness, and rehabilitation. Synth Lect Assist Rehabil Heal Technol. (2011) 1:1-94. doi: 10.2200/S00380ED1V01Y201108ARH002

89. Akbar A, Kousiouris G, Pervaiz H, Sancho J, Ta-Shma P, Carrez F, et al. Realtime probabilistic data fusion for large-scale IoT applications. IEEE Access. (2018) 6:10015-27. doi: 10.1109/ACCESS.2018.2804623

90. Groseclose SL, German RR, Nsubuga P. Evaluating Public Health Surveillance. Prin Pract Publ Health Surveil. (2010) 166-197. doi: 10.1093/acprof:oso/9780195372922.003.0008

91. ecobee. Donate your Data | ecobee | Smart Home Technology. (2018). Available online at: https://www.ecobee.com/donateyourdata/ (accessed January 24, 2019).

92. Koskimäki H, Kinnunen H, Kurppa T, Röning J. How Do We Sleep - a Case Study of Sleep Duration and Quality Using Data from Oura Ring. New York, NY: Association for Computing Machinery, Inc. (2018).

93. Baloch Z, Shaikh FK, Unar MA. A context-aware data fusion approach for health-IoT. Int J Inf Technol. (2018) 10:2415. doi: 10.1007/s41870-018-0116-1

94. Mora H, Gil D, Terol RM, Azorín J, Szymanski J. An IoT-Based computational framework for healthcare monitoring in mobile environments. Sensors. (2017) 17:2302. doi: 10.3390/s17102302

95. Iwendi C, Kumar Reddy PM, Reddy TG, Lakshmanna K, Kashif Bashir A, Piran J. A Metaheuristic optimization approach for energy efficiency in the IoT networks. Softw Pract Exp. (2020) 51: 2558-71. doi: 10.1002/spe. 2797

96. Yuan M, Boston-Fisher N, Luo Y, Verma A, Buckeridge DL. A systematic review of aberration detection algorithms used in public health surveillance. J Biomed Inform. (2019) 94:103181: doi: 10.1016/j.jbi.2019.103181

97. Faverjon C, Berezowski J. Choosing the best algorithm for event detection based on the intended application: a conceptual framework for syndromic surveillance. J Biomed Inform. (2018) 85:126-35. doi: 10.1016/j.jbi.2018.08.001

98. Jalali N, Sahu K, Oetomo A, Morita P. Understanding user behavior through the use of unsupervised anomaly detection: proof of concept using internet of things smart home thermostat data for improving public health surveillance. JMIR Mhealth Uhealth. (2020) 8:e21209: doi: 10.2196/21209

99. Natarajan A, Su HW, Heneghan C. Assessment of physiological signs associated with COVID-19 measured using wearable devices. npj Digit Med. (2020) 3:156. doi: 10.1038/s41746-020-00363-7

100. Kogan NE, Clemente L, Liautaud P, Kaashoek J, Link NB, Nguyen AT, et al. An early warning approach to monitor COVID-19 activity with multiple digital traces in near real-time. Sci Adv. (2021) 7:eabd6989. doi: 10.1126/sciadv.abd6989

101. Jeong $\mathrm{H}$, Rogers JA, Xu S. Continuous on-body sensing for the COVID-19 pandemic: gaps and opportunities. Sci Adv. (2020) 6:eabd4794. doi: 10.1126/sciadv.abd 4794

102. Mishra T, Wang M, Metwally AA, Bogu GK, Brooks AW, Bahmani A, et al. Early detection of COVID-19 using a smartwatch. medRxiv. (2020) eabd4794. doi: 10.1101/2020.07.06.2014 7512

103. Fitbit. Early Findings From Fitbit COVID-19 Study Suggest Fitbit Devices Can Identify Signs of Disease at Its Earliest Stages - Fitbit Blog. (2020). Available online at: https://blog.fitbit.com/early-findings-covid-19-study/ (accessed September 10, 2020).

104. Xu C, Yang Y, Gao W. Skin-Interfaced Sensors in Digital Medicine: from Materials to Applications. Matter. (2020) 2:1414-45. doi: $\quad 10.1016 /$ j.matt.2020.0 3.020

105. Rahman MS, Peeri NC, Shrestha N, Zaki R, Haque U, Hamid SHA. Defending against the novel coronavirus (COVID-19) outbreak: how can the Internet of Things (IoT) help to save the world? Heal Policy Technol. (2020) 9:136-8. doi: 10.1016/j.hlpt.2020.04.005

106. Nikoleli GP, Siontorou CG, Nikolelis DP, Bratakou S, Karapetis $\mathrm{S}$, Tzamtzis N. Biosensors based on microfluidic devices lab-ona-chip and microfluidic technology. Nanotechnol Biosensors. (2018) 375-94. doi: 10.1016/B978-0-12-813855-7.00013-1

107. Patra B, Sharma M, Hale W, Utz M. Time-resolved non-invasive metabolomic monitoring of a single cancer spheroid by microfluidic NMR. Sci Rep. (2021) 11:53. doi: 10.1038/s41598-020-79693-1

Conflict of Interest: The authors declare that the research was conducted in the absence of any commercial or financial relationships that could be construed as a potential conflict of interest.

Publisher's Note: All claims expressed in this article are solely those of the authors and do not necessarily represent those of their affiliated organizations, or those of the publisher, the editors and the reviewers. Any product that may be evaluated in this article, or claim that may be made by its manufacturer, is not guaranteed or endorsed by the publisher.

Copyright (C) 2021 Sahu, Majowicz, Dubin and Morita. This is an open-access article distributed under the terms of the Creative Commons Attribution License (CC BY). The use, distribution or reproduction in other forums is permitted, provided the original author(s) and the copyright owner(s) are credited and that the original publication in this journal is cited, in accordance with accepted academic practice. No use, distribution or reproduction is permitted which does not comply with these terms. 